\title{
Glutamate-like Immunoreactivity in Identified Neuronal Populations of Insect Nervous Systems
}

\author{
Gerd Bicker, Sabine Schäfer, Ole P. Ottersen, and Jon Storm-Mathisen \\ Institut für Tierphysiologie-Neurobiologie der Freien Universität Berlin, 1000 Berlin 33, FRG and Anatomical Institute, \\ University of Oslo, 0162 Oslo 1, Norway
}

\begin{abstract}
Glutamate is considered to be the most likely transmitter candidate at excitatory synapses onto skeletal muscles of insects. We investigated the distribution of glutamate-like immunoreactivity (Glu-LI) in identified motor neurons of glutaraldehyde-fixed metathoracic ganglia of the locust in paraffin serial sections. The presumably glutamatergic fast and slow extensor tibiae motor neurons show Glu-LI, whereas other cells, including the GABAergic common inhibitory motor neurons and the cluster of octopaminergic dorsal unpaired median cells, show rather low levels of staining. Immunoreactivity of the fast extensor tibiae motor neuron is located in soma, neurites, axon, and the terminal arborizations. A double-labeling experiment on sections of the locust metathoracic ganglion showed that antisera against glutamate and GABA discriminate between the presumably glutamatergic and GABAergic motor neurons and that GABALI-positive neurons are low in Glu-LI. The results suggest that Glu-LI can be used as a marker for detecting potential glutamatergic neurons in insects under the present conditions.
\end{abstract}

Application of the glutamate antiserum to sections of the honeybee brain revealed Glu-LI in motor neurons but also in certain interneurons. The most prominent populations of GluLI-positive cells were the monopolar cells and large ocellar interneurons, which are first-order interneurons of the visual and ocellar system. Several groups of descending interneurons also showed Glu-LI. The distributions of Glu-LI and GABA-LI are complementary in locust and bee ganglia. The high level of Glu-LI in certain interneuronal populations, as well as in identified glutamatergic motor neurons, suggests that insect central nervous systems may contain glutamatergic neuronal pathways.

The amino acid glutamate scrves as a neurotransmitter in both vertebrate and invertebrate nervous systems. Glutamate is thought to be released in a large proportion of central synapses in the vertebrate brain and spinal cord (Hertz et al., 1983; Fonnum, 1984). In invertebrates, glutamatergic neurotransmission

\footnotetext{
Received June 8, 1987; revised Aug. 19, 1987; accepted Oct. 8, 1987.

This work was supported by grants from the Deutsche Forschungsgemeinschaft and the Norwegian Research Council for Science and the Humanities. We wish to thank many of our colleagues for helpful comments, Sybille Schaare for photographic assistance, and Dr. Manfred Eckert, Friedrich Schiller Universität Jena, for advice on the double-labeling procedure.

Correspondence should be addressed to Gerd Bicker, Institut für Tierphysiologie--Neurobiologie der Freien Universität Berlin, Königin-Luise-Str. 28/30, 1000 Berlin, FRG.

Copyright (C) 1988 Society for Neuroscience $0270-6474 / 88 / 062108-15 \$ 02.00 / 0$
}

has been demonstrated at the neuromuscular junction of arthropods (Otsuka et al., 1967; Usherwood et al., 1968; CullCandy, 1976; Usherwood, 1981), but not as yet at central synapses. Amino acid transmitters such as $\gamma$-aminobutyric acid (GABA) and glutamate can be visualized within specific populations of neurons with antisera raised against the amino acid conjugated to protein carriers (Storm-Mathisen et al., 1983; Ottersen and Storm-Mathisen, 1984, 1987; Seguela et al., 1984; Hodgson et al., 1985; Storm-Mathisen and Ottersen, 1986, 1988).

The immunocytochemical localization of a neuroactive compound in a neuron does not necessarily imply that it is releasable as a transmitter. This is especially true for an amino acid like glutamate, which is a component of several metabolic pathways within nerve cells (Hertz et al., 1983). Skeletal muscles in crustaceans and insects are innervated by a small number of identified motor neurons (Hoyle, 1983), most of which are considered to be glutamatergic. Since glutamate and the natural transmitter have identical postsynaptic actions on locust muscle (Usherwood et al., 1968; Usherwood, 1981), and most of the criteria for identification of transmitters (Werman, 1966) have been met, there seems little doubt that glutamate is in fact a transmitter at excitatory synapses on locust muscle (Piek, 1985).

The extensor tibiae muscle of the locust hindleg is innervated from the metathoracic ganglion (Hoyle, 1955a, b; Pearson and Bergman, 1969; Burrows and Hoyle, 1973; Hoyle and Burrows, 1973) and has been used as a system to study neuromuscular transmission. This muscle is innervated by 4 uniquely identified neurons, the slow extensor tibiae motor neuron (SETi), the fast extensor tibiae motor neuron (FETi), the dorsal unpaired median cell to extensor tibiae (DUMETi), and a branch of a common inhibitory motor neuron (CI). All 4 neurons have their somata and arborizations within the metathoracic ganglion. Extensive data indicate that SETi and FETi use glutamate, that CI uses GABA as neurotransmitter, and that DUMETi potentiates neuromuscular transmission by release of octopamine (Usherwood and Grundfest, 1965; Emson et al., 1974; Hoyle, 1975, 1983; Usherwood and Cull-Candy, 1975; Evans and O'Shea, 1977; Goodman and Spitzer, 1979). Several neuropeptides and biogenic amines modulate tension in the extensor tibiae muscle, one of which is the neuropeptide proctolin, which is thought to colocalize with glutamate in SETi (O'Shea, 1985).

We compared glutamate-like (Glu-LI) and GABA-like (GABA-LI) immunoreactivity in excitatory and inhibitory motor neurons of the locust metathoracic ganglion. The finding that Glu-LI is selectively concentrated in identified excitatory motor neurons prompted our investigation of Glu-LI in cell populations of the worker bee brain. Thus far, immunocyto- 
chemical studies on the distribution of amino acids in insect brains have been restricted to the investigation of GABA-LI (Ammermüller and Weiler, 1985; Bicker et al., 1985; Hoskins et al., 1986; Meyer et al., 1986; Homberg et al., 1987). However, glutamate seems to be the most abundant free amino acid in the nervous system of insects (Pitman, 1985), and the analysis of free amino acids in the bee brain shows that the glutamate content of $37 \mu \mathrm{mol} / \mathrm{gm}$ wet weight is 4 times higher than that of GABA (Frontali, 1964). Therefore, we extended our previous studies on GABA-LI in the brain of the honeybee (Schäfer and Bicker, 1986a, b; Bicker et al., 1987) to a description of GluLI. The present study allows a comparison of the distributions of GABA-LI and Glu-LI within an insect brain. The results suggest the presence of glutamatergic neurons in the central nervous system of insects.

\section{Materials and Methods}

Immunocytochemical staining was performed on locust (Locusta migratoria) metathoracic ganglia, the extensor tibiae muscle of the hindleg, and brains of worker bees.

A fixative composed of glutaraldehyde (3\%) dissolved in sodium phosphate buffer (NaPi, $0.1 \mathrm{~m}, \mathrm{pH} 7.4)$ was injected into the thorax of live bees. The brains were subsequently dissected out of the head capsule and fixed for $45 \mathrm{~min}$ in the same fixative. After rinsing in $\mathrm{NaPi}$ the tissue was dehydrated in increasing grades of ethanol and then infiltrated with paraffin. Serial sections, $10 \mu \mathrm{m}$ thick, were cut, mounted on slides, deparaffinized, and processed according to the peroxidase-antiperoxidase (PAP) method (Sternberger, 1979). The sections were incubated overnight at $4{ }^{\circ} \mathrm{C}$ with the glutamate antiserum diluted in a Tris-buffered saline (TBS, $0.1 \mathrm{M}$ Tris- $\mathrm{HCl}, 0.3 \mathrm{M} \mathrm{NaCl}, 0.1 \%$ Triton X-100, $1 \%$ normal goat serum, $\mathrm{pH}$ 7.4) at a dilution of 1:1000. After rinsing with TBS the sections were incubated with goat anti-rabbit IgG (Sigma) diluted in TBS 1:40, for $1 \mathrm{hr}$ at room temperature. This was followed by another rinse with TBS and an incubation at room temperature in the PAP complex (Dakopatts; diluted 1:100 in TBS) for $1 \mathrm{hr}$. The sections were then washed in $\mathrm{NaPi}$ and treated with 3,3'-diaminobenzidine (DAB; Sigma; $25 \mathrm{mg} / 100 \mathrm{ml} \mathrm{NaPi})$ and $\mathrm{H}_{2} \mathrm{O}_{2}(0.01 \%)$. They were subsequently dehydrated, cleared in xylene, and mounted in Entellan (Merck). During initial exploratory work we employed a simpler staining procedure with a secondary HRP-labeled goat anti-rabbit IgG (Nordic Immunology; diluted 1:200 in TBS).

The immunocytochemical staining of locust thoracic ganglia and extensor tibiae muscle followed exactly the same histological protocol as that given for the nervous system of the bee. The live insects were injected with the fixative and thoracic ganglia were exposed by a dorsal dissection. The metathoracic ganglion was taken out of the body cavity and processed according to our standard procedure. The hindlegs were removed by cutting through the coxa, and fixative was injected into the femur at the joint between femur and tibia. The extensor tibiae muscle was separated from the surrounding cuticula and fixed for $45 \mathrm{~min}$.

We performed immunocytochemical double-labelings with antisera against glutamate and GABA on the same sections. This method, described in detail by Vandesande (1983), comprised 2 sequential steps. First the tissue was treated with the glutamate antiserum, and the presence of Glu-LI was detected as the stable brown precipitate that the PAP complex formed with DAB as a substrate. The slides were coverslipped in $\mathrm{NaPi} /$ glycerol 1:9, and, after observation and photographing chosen sections, again washed in NaPi. All the bound antibodies were then removed from the tissue by electrophoresis in glycine- $\mathrm{HCl}$ buffer for $1 \mathrm{hr}$ at $40 \mathrm{~mA}$. The electrophoresis chamber contained a mixture of $25 \mathrm{ml} 0.2 \mathrm{M}$ glycine-IICl buffer, pH 2.2 , plus $50 \mathrm{ml}$ dimethylformamide plus $100 \mathrm{ml} \mathrm{H}_{2} \mathrm{O}$, and was connected to the electrode compartments by filter paper. Both electrode chambers were filled with a solution of $0.2 \mathrm{M}$ glycine- $\mathrm{HCl}$ buffer, $\mathrm{pH} 2.2$, containing $0.5 \mathrm{M} \mathrm{NaCl}$ to decrease resistance. After rinsing in $\mathrm{NaPi}$, the sections were processed in a second step with the GABA antiserum diluted 1:1000. In this step we used chloronaphthol (100 mg of 4-chloro-1-naphthol dissolved in $10 \mathrm{ml}$ ethanol plus $190 \mathrm{ml}$ of $0.05 \mathrm{M}$ Tris- $\mathrm{HCl}, \mathrm{pH} 7.6$, plus $5 \mathrm{ml}$ of $0.3 \%$ $\mathrm{H}_{2} \mathrm{O}_{2}$ ) as a substrate for the PAP complex, which yielded a blue reaction product. Slides were rinsed in $\mathrm{NaPi}$ and coverslipped in $\mathrm{NaPi}$ /glycerol. Thus the brown and blue stains indicative of Glu-LI and GABA-LI, respectively, could be viewed simultaneously on the same section. This procedure offers an additional advantage in that previously unnoticed areas can be photographed and the blue reaction product can be removed by a series of graded ethanol. Thus it is possible to recover the original ethanol-stable Glu-LI that may underlie the GABA-LI. As a control for the removal of bound antibodies, we subjected sections to electrophoresis after incubation with the primary antiserum. After washing, incubation in secondary antiserum and PAP complex, and treatment with chloronaphthol we found no selective staining. However, an unspecific darkening of the tissue was always evident. An enhancement of the DAB staining, depending on the duration of the subsequent chloronaphthol processing, was therefore unavoidable in some double-labeling experiments.

We used the glutamate and GABA antisera nos. 13 and 26 described by Storm-Mathisen et al. (1983) and Ottersen and Storm-Mathisen (1984). The GABA antiserum showed identical staining in the bee brain and locust metathoracic ganglion as that described for the GABA antiserum used by Hoskins et al. (1986), which was employed in an earlier study in bee brain (Bicker et al., 1985; Schäfer and Bicker, 1986a, b). The application of the GABA antiserum to sections of locust thoracic nerves confirmed the distribution of GABA-LI-positive axon profiles that was obtained with another antiserum by Watson (1986). The following controls were performed in locust and bee tissue. Glutamateglutaraldehyde and GABA-glutaraldehyde complexes were prepared as described by Ottersen et al. (1986). Staining with the glutamate antiserum was completely abolished by preadsorbing with the glutamate complex at a limiting concentration of $100 \mu \mathrm{M}$ in the bee or $200 \mu \mathrm{M}$ in locust tissue. Preadsorption of the glutamate antiserum with the GABA complex at the same concentrations did not reduce the staining.

\section{Results}

\section{Fixation procedure}

The antisera were generated against glutamate or GABA, coupled to BSA with glutaraldehyde (Storm-Mathisen et al., 1983). Since it is difficult to cut paraffin sections of tissue fixed with a high concentration of glutaraldehyde, the concentration was kept at $3 \%$. Unlike the GABA antiserum, which was relatively insensitive to the addition of paraformaldehyde to the fixative, the selective staining with the glutamate antiserum was reduced by the presence of paraformaldehyde in the fixative. Therefore, we chose glutaraldehyde without the addition of paraformaldehyde as a fixative in order to match the conditions used for the preparation of the immunogen. Some variability in staining from animal to animal was also found when ganglia were dissected in Ringer's solution and then fixed, and for this reason we tried to fix the tissue as rapidly as possible by direct injection of the fixative into the hemolymph of the animal. Even though both the glutamate and GABA antisera were used at concentrations of $1: 1000$, the latter gave a higher contrast between stained and unstained cells than the former. Thus Glu-LI was more evenly distributed among neurons than was GABA-LI, reflecting the multiple roles of the former amino acid in cell metabolism.

\section{Locust metathoracic ganglion and extensor tibiae muscle}

The thoracic ganglia of the locust contain some identified neurons, for which there is good evidence that they release a particular neurotransmitter. Thus we chose the metathoracic ganglion in order to compare Glu-LI in identified glutamatergic and nonglutamatergic motor neurons that innervate the extensor tibiae muscle. This jumping muscle of the locust provides perhaps the most intensivly studied insect neuromuscular system (Evans and O'Shea, 1977; Hoyle, 1983; O'Shea, 1985; Piek, 1985). The FETi is, with its characteristic shape, position, and a soma of $80 \mu \mathrm{m}$ in diameter, the largest identified neuron in the metathoracic ganglion. A horizontal section through the metathoracic ganglion shows intense Glu-LI in FETi (Fig. 1a). 
2110 Bicker et al. - Glu-like Immunoreactivity in Insect CNS
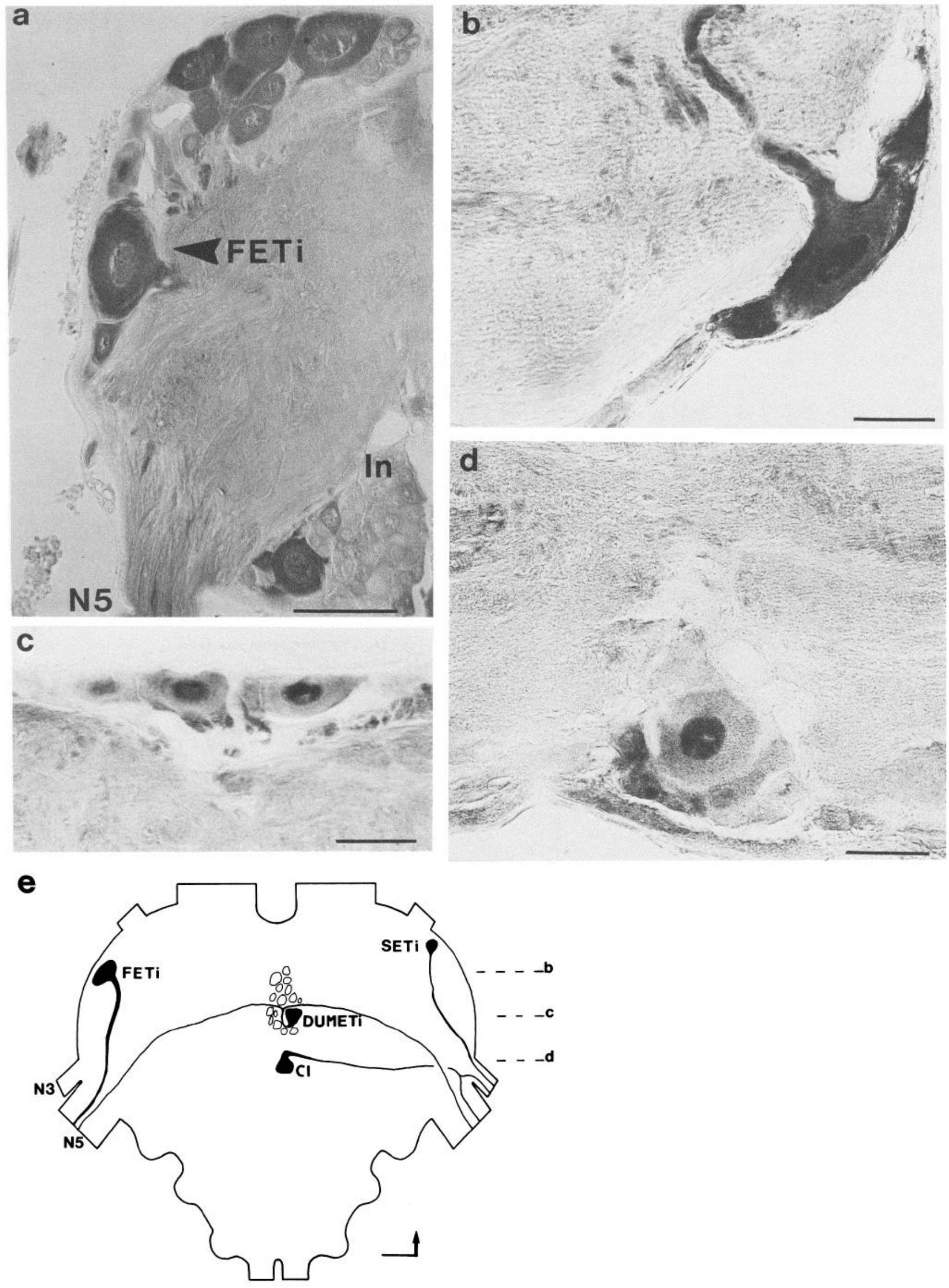

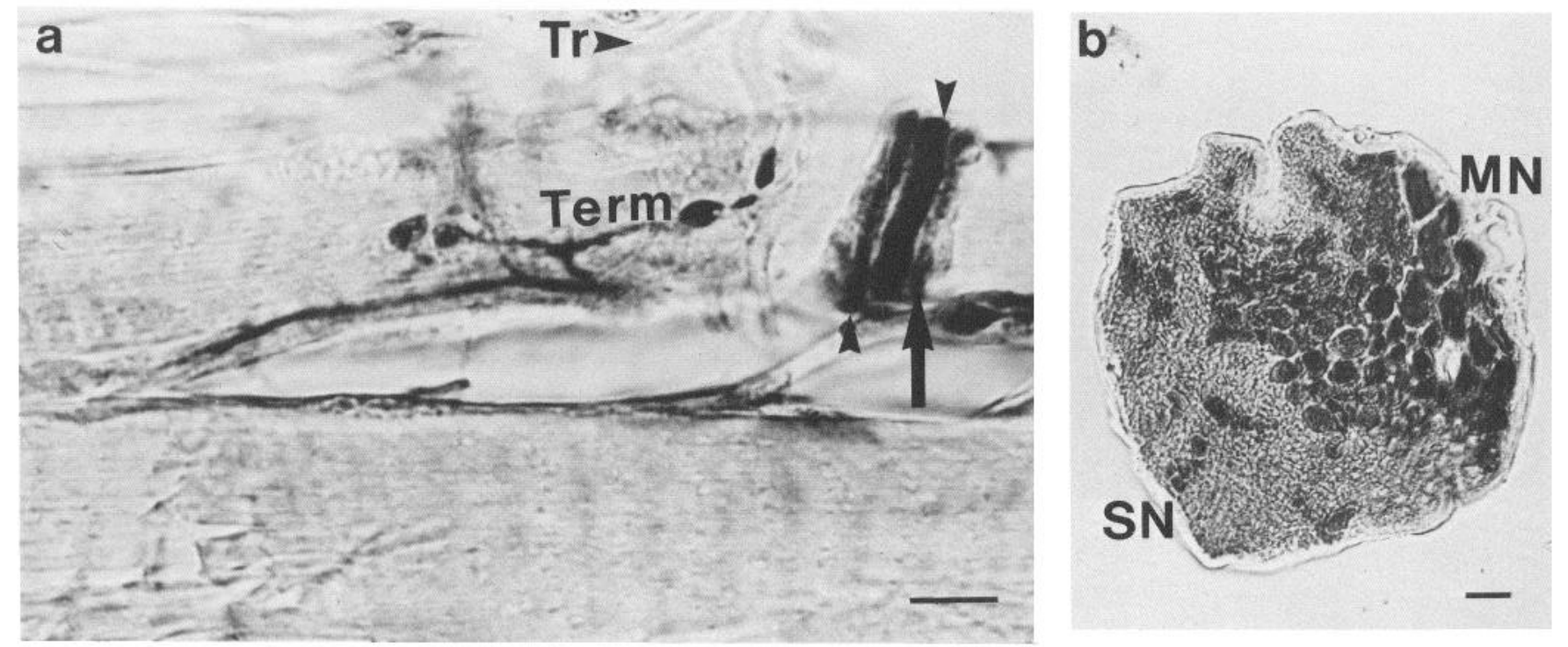

Figure 2. a, Section through a fiber of the extensor tibiae muscle in the ventral outside region d. Glu-LI in 2 axons (arrowheads) of an axon bundle. A third axon (arrow) can faintly be discerned within the bundle. The surface of the fiber is covered by Glu-LI varicose-appearing axon terminals $(\mathrm{Term}) . \mathrm{Tr}$, trachea. $b$, Cross section of leg nerve 5 showing Glu-LI in the large-diameter motor axons $(M N)$ and a low level of staining in the smaller-diameter sensory neurons $(S N)$. All scales, $10 \mu \mathrm{m}$.

Glu-LI was detectable in the soma, the primary neurite (Fig. $1 b$ ), the arborizations within the neuropile, and the axon leaving the ganglion through nerve 5 . Similarly, Glu-LI was detected in other motor neurons (Fig. 1a). The Glu-LI within the motor neurons contrasts with the low level of staining within a group of somata that, judging by their size, belong to interneurons (Fig. 1a). However, immunoreactive fibers were found in the connectives, indicating that other interneurons show Glu-LI. A description of these interneurons and their possible synaptic connections will be given in a separate paper.

In order to compare Glu-LI in identified neurons using glutamate, octopamine, and GABA as likely transmitters, we investigated Glu-LI in FETi, dorsal unpaired median (DUM) cells, and CI. Figure 1, $b-d$, was prepared from transverse serial sections processed on the same slide and photographed with identical exposure. The plane of sectioning and the approximate position of the somata are shown in Figure 1e. We could not identify DUMETi unequivocally, because the DUM cells can change their position within the soma rind from animal to animal, and we did not perform intracellular dye labeling in order to trace the peripheral projections of the DUMETi. However, inspection of the large-diameter cell bodies of the DUM cell group (Fig. $1 c$; median soma cluster in Fig. 1e) over several sections showed less Glu-LI within these neurons than in FETi (Fig. 1b). The detailed morphology of the common inhibitory motor neuron (according to the terminology of Hale and Burrows, $\left.1985 ; \mathrm{CI}_{1}\right)$ that evokes inhibitory junction potentials in the extensor tibiae has been described (Watson et al., 1985).
The somata of the $2 \mathrm{CI}$ neurons, innervating the left and right side, are located on the ventral side of the ganglion close to the midline, and are set apart from other large-diameter motoneuronal somata. They lie adjacent to each other, and are sometimes arranged with one anterior in tandem to the other. Biochemical studies confirmed that the somata of inhibitory motor neurons contain glutamate decarboxylase (Emson et al., 1974), and GABA-LI of the CI has been demonstrated (Watson, 1986). The perikaryon of a CI (Fig. 1d) showed less Glu-LI than did the FETi, while the nuclei of CI and FETi were both stained. The nuclear staining could be inhibited by preadsorption of the antiserum with the glutamate-glutaraldehyde complex.

Sections of the nerves leaving the ganglion gave the impression that Glu-LI is enriched in the axons of motor neurons relative to their somata. The difference in staining intensity may be due to a more rapid access of the fixative to the extended nerves than to the ensheathed ganglion, but a difference in the in vivo concentration of glutamate remains a distinct possibility. A cross section through nerve 5 (Fig. $2 b$ ) shows strong Glu-LI in the large-diameter motor axons, as opposed to the low level of reactivity in the small-diameter sensory fibers.

Insect skeletal muscle fibers are, unlike those of vertebrates, multiterminally innervated (Hoyle, 1983; Piek, 1985). Excitatory motor neurons are thought to release glutamate at synapses formed by motor terminals, which are evenly distributed along the length of the fiber (Usherwood, 1974). Sections were taken from several regions of the extensor tibiae muscle, and in particular from the ventral outside regions $d$ and e (Hoyle, 1978),

Figure 1. Glu-LI in identified neurons of the locust metathoracic ganglion. $a$, Horizontal section shows Glu-LI in processes and somata of motor neurons and the fast extensor tibiae motor neuron (FETi). A population of interneurons (In) median to leg nerve 5 (N5) is unlabeled. $b-d$, GluLI in neurons with identified transmitter candidates. Transverse sections of the metathoracic ganglion were run through the immunocytochemical staining procedure on the same slide and photographed under identical exposure. $b$, Immunoreactivity in primary neurite and soma of presumably glutamatergic FETi. $c$, Immunoreactivity in somata of octopaminergic dorsal unpaired median cells (DUM). $d$, Immunoreactivity in soma of GABAergic common inhibitory motor neuron that innervates the extensor tibiae. Scale, $50 \mu \mathrm{m}(a-d)$. $e$, Schematic drawing of a horizontal view of the metathoracic ganglion, showing the planes of transverse sections in $b-d$. $C I$, common inhibitor; DUMETi, dorsal unpaired median cell to extensor tibiae; FETi, fast extensor tibiae; $S E T i$, slow extensor tibiae; $N 3$, nerve 3; $N 5$, nerve 5. Arrow points towards anterior. Scale, $100 \mu$ m. 
which are innervated by all 4 motor neurons. Strong immunoreactivity was found in the 2 axonal arborizations of largest diameter (Fig. $2 a$ ), which belong to FETi and SETi. The varicose terminal arborizations of these 2 axons were also strongly immunoreactive and ramified across the muscle fibers (Fig. 2a). This finding confirms that the presumably glutamatergic FETi not only shows Glu-LI in the cell body and axon but also in the neuromuscular terminals. Since we could not identify the soma of SETi from other Glu-LI-positive motoneuronal somata, the demonstration of Glu-LI in this neuron is restricted to axon and terminals.

Glu-I I-immunoreactive branches of the motor neurons were sometimes accompanied by arborizations with a fainter reactivity. A branch with barely visible reactivity (arrow) can also be discerned in the axon bundle of Figure $2 a$. We suspected that these arborizations belonged to the GABAergic CI. This was confirmed using a double-labeling procedure with the glutamate antiserum and GABA antiserum no. 26, characterized by Ottersen and Storm-Mathisen (1984). The latter antiserum gave a similar staining pattern of the locust metathoracic ganglion and nerves as the GABA antiserum used by Watson (1986). The purpose of this double-labeling experiment was 2-fold. First, we wanted to test whether the antisera against glutamate and GABA can differentiate between neurons identified as glutamatergic and GABAergic on other grounds. Second, the doublelabcling cxpcriment allowed a direct evaluation of the level of Glu-LI in many GABA-LI interneurons within the same section. The double-labeling experiment was performed on transverse sections of the metathoracic ganglion (Fig. 3, $a-d$ ) and sections of the distal extensor tibiae muscle (Fig. 3, $e-h$ ).

A section at the level of the midline of the ganglion (Fig. $3 a$ ) demonstrates again (see Fig. $1 d$ ) a rather low level of Glu-LI in a transsected soma of a CI as compared to that of several GluLI somata in the vicinity. After the electrophoretic removal of bound antibodies from the section, the GABA antiserum was applied and visualized by a blue reaction product. Thus Glu-LI (brown) and GABA-LI (blue) can be viewed simultaneously in Figure $3 b$. The blue staining indicates GABA-LI in the soma of $\mathrm{CI}$ and several other unidentified somata. A transverse section posterior to the exit of nerve 5 (Fig. $3, c, d$ ) provides an overview of the brown Glu-LI and blue GABA-LI staining in the neuropile and soma rind of the ganglion. The large Glu-LI somata, presumably belonging to motor neurons, are embedded among the smaller GABA-LI interneuronal somata. Unlabeled somata can also be discerned in Figure 3, $a-d$. A comparison of Figure 3, $a, b$ and $c, d$ proves that GABA-LI cells are low in Glu-LI.

We encountered one technical difficulty with this double-labeling protocol. The reaction that develops the blue staining indicative of GABA-LI also darkens, and thus intensifies, the Glu-LI. Cross sections of nerves with the intensely stained GluI. I motor axons (see Fig. 2b) turn rather dark after subsequent GABA immunocytochemistry. This yields a rather low color contrast between Glu-LI and GABA-LI axons that is difficult to reproduce photographically. Thus we performed the doublelabeling on tangential sections of extensor tibiae muscle fibers. In the distal accessory extensors 135 we found Glu-LI axonal arborizations that were accompanied by faintly stained branches (Fig. 3,e, g). However, the branches that were only weakly GluLI-positive showed strong GABA-LI (Fig. 3, $f, g$ ). This distal part of the extensor tibiae muscle contains only the arborizations of SETi, which are accompanied by CI (Hoyle, 1978, 1983; Piek
1985). Therefore, we conclude that the brown Glu-LI arborizations shown in Figure $3, e-h$, revealed SETi, while the blue fibers showed the GABAergic CI. Thus the 2 antisera are able to differentiate between presumed GABAergic and glutamatergic neurons.

\section{Brain of the honeybee}

Having been convinced that the glutamate antiserum indeed stains putative glutamatergic neurons in an insect nervous system, we applied the antiserum to sections of the bee brain. The brain and the subesophageal ganglion of the bee comprise several neuropile areas, some of which contain the processes of motor neurons. These motor neurons are responsible for the movement of the antennae, the various mouth parts, and the head with respect to the thorax. Location and shape of the motor neurons have been determined by degeneration studies and by backfilling the axonal projections through the nerve with cobalt chloride (Pareto, 1972; Suzuki, 1975; Rehder, 1987). The antennal lobe, a sensory integration center of the deutocerebrum, gives rise to a large, mainly sensory, antennal nerve that is accompanied by the branches of a smaller motor nerve to the antennal muscles (Fig. 4a). Pareto (1972) describes about 20 motor axons supplying the antennal muscles, 6 running in the large sensory antennal nerve, while the rest extend through the small motor nerve. The fibers of this inner antennal motor nerve (Parcto, 1972) join the efferent fibers of the antennal nerve within the deutocerebrum posterior to the antennal lobes. The dorsal lobe, an egg-shaped neuropile posterior to the antennal lobe (Fig. $4 a$ ), is the motor center of the deutocerebral parts of the brain. It receives mainly antennal mechanosensory projections and is the origin of the antennal motor axons (Pareto, 1972; Suzuki, 1975). The efferent fibers separate within the deutocerebrum, the majority extending through the inner antennal motor nerve (Pareto, 1972; Suzuki, 1975), while some join the sensory antennal nerve.

The deutocerebral distribution of Glu-LI is shown in Figure $4, b-e$. Only a few Glu-LI fibers and somata could be discerned in the antennal lobe (Fig. 4b). A sagittal section reveals the projections of antennal motor neurons in the ventral part of the antennal and dorsal lobes (Fig. $4 c$ ). The sensory projections from the antennae were not stained. We counted ca. $10 \mathrm{Glu}-\mathrm{LI}$ axon profiles in cross sections of the inner antennal motor ncrvc. GluLI axons of the antennal motor neurons can be clearly seen entering the muscle fibers (Fig. 4e). In cross sections of the sensory antennal nerve (Fig. $4 d$ ), our method revealed 3 strongly labeled Glu-LI motor axons and patches of less intense Glu-LI that could not be resolved into distinct fibers.

\section{Optic lobes}

The photoreceptors of the compound eyes provide the sensory input for 3 columnar organized neuropiles: the lamina, medulla, and lobula (Fig. 4a). Most retinula cell axons terminate in the first optic ganglion, the lamina, while 3 long visual fibers of each ommatidium project through the lamina and outer chiasma into a distal layer of the medulla (Ribi, 1975). Glu-LI was not detected between the basement membrane and the fenestrated layer of the distal lamina (Fig. 5). This indicates that the axons of the retinula cells were not stained by Glu antiscrum. The fenestrated layer contains the somata of the monopolar cells that are clustered around tracheal invaginations (Fig. $5 b$ ). The somata of the monopolar cells and their projections through the 

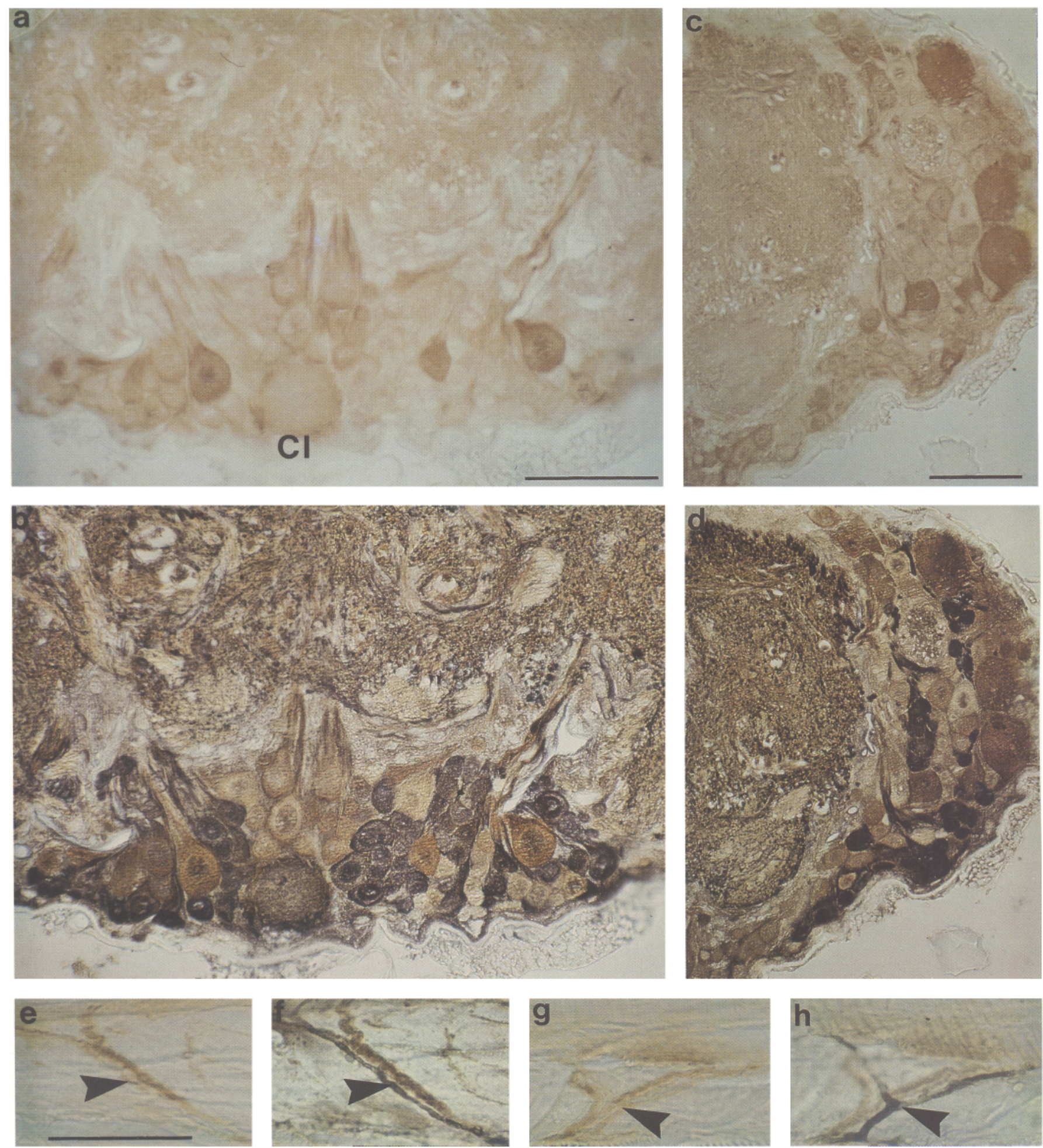

Figure 3. Sequential double-labeling experiment performed in transverse sections of locust metathoracic ganglion showing Glu-LI (brown) and GABA-LI (blue). $a$, The GABAergic common inhibitory neuron $(C I)$ shows less immunoreactivity than the other Glu-LI-positive somata. $b$, GluLI (brown) and GABA-LI (blue) on the same section. Besides the soma of CI, smaller somata of interneurons show GABA-LI. Note the low level of Glu-LI within these interneurons. $c$, Transverse section of the hemiganglion posterior to the entrance of nerve 5, showing the distribution of Glu-LI in soma rind and neuropile. $d$, Glu-LI in large-diameter somata of motor neurons and GABA-LI in smaller-diameter somata of interneurons. Scales $(a-d), 100 \mu \mathrm{m} . e-h$, Section through distal extensor tibiae muscle showing arborizations of common inhibitory (arrow) and slow extensor tibiae motor neurons. The CI that can be identified by its blue staining shows a much lower level of Glu-LI $(e, g$, arrowhead $)$ than does the SETi. Scales $(e-h), 50 \mu \mathrm{m}$. 

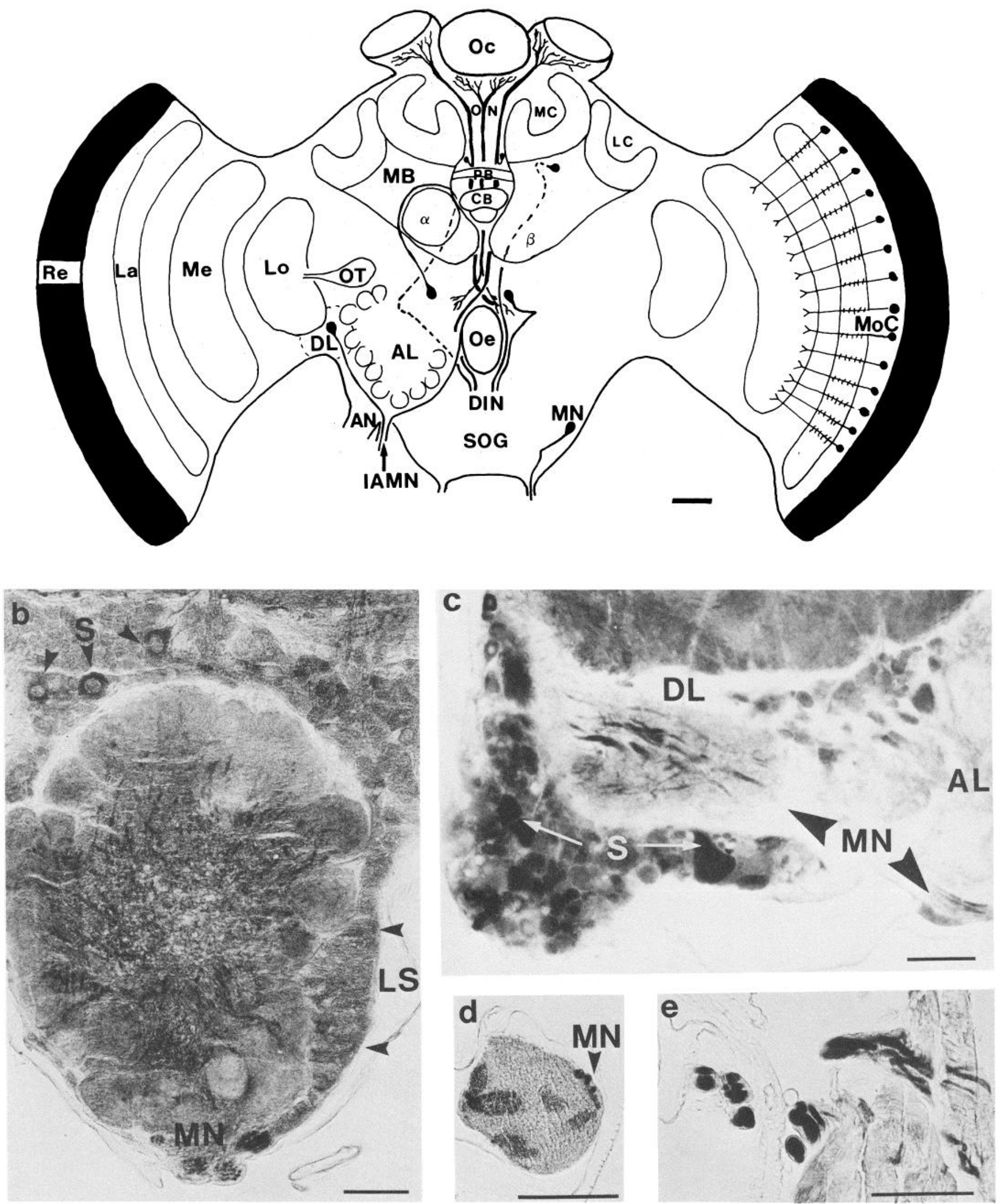

Figure 4. Glu-LI in the brain of the honeybee. $a$, Schematic drawing of identified Glu-LI-positive neuronal populations in the brain and subesophageal ganglion of the bee in a frontal view. Left hemisphere shows anterior parts of the brain at the level of the antennal lobe, while the right hemisphere shows a more posterior view, including the subesophageal ganglion. $A L$, antennal lobe; $A N$, antennal nerve; $\alpha, \alpha$-lobe; $\beta, \beta$-lobe; $C B$, central body; $D I N$, descending interneurons; $D L$, dorsal lobe; $I A M N$, inner antennal motor nerve; $L a$, lamina; $L o$, lobula; $L C$, lateral calyx; 

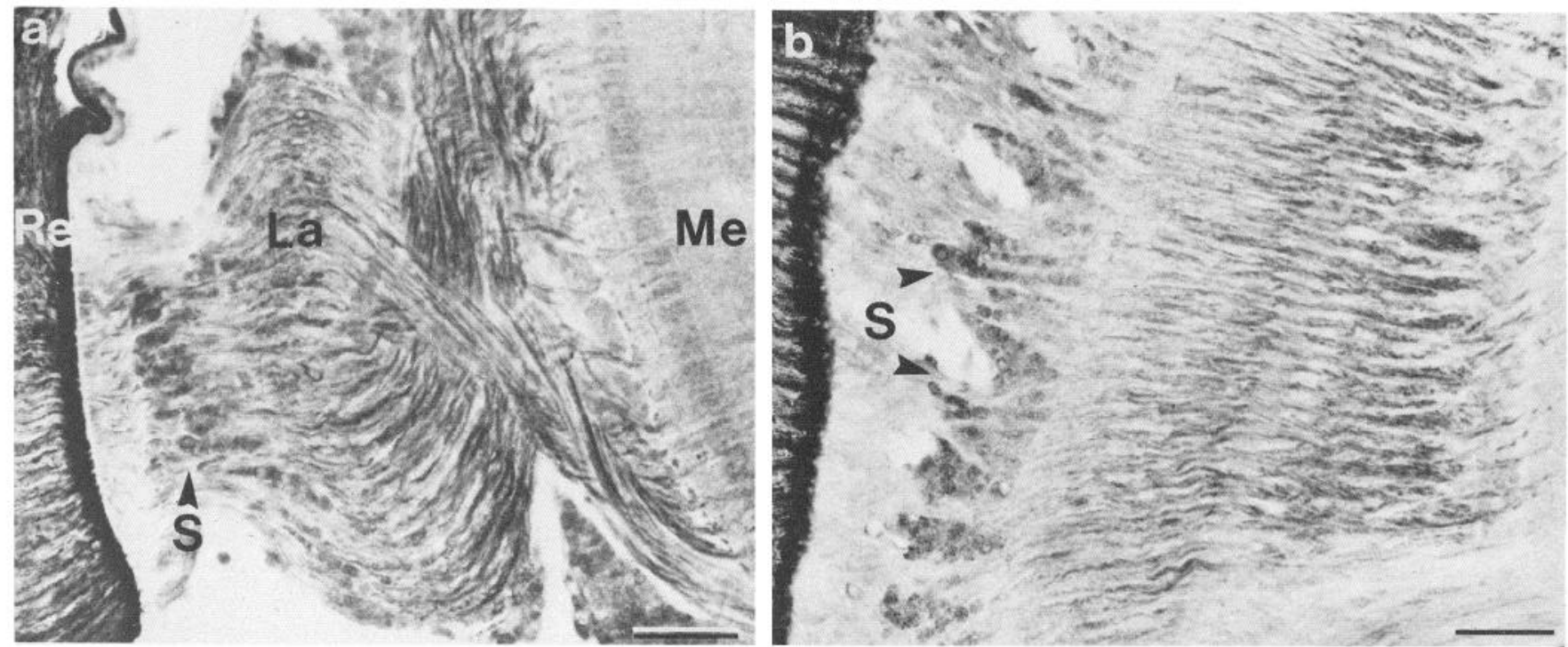

Figure 5. a, Horizontal section through the retina $(R e)$, lamina $(L a)$, and the distal medulla $(M e)$. Glu-LI monopolar cells with somata $(S)$ in the fenestrated layer send their projection fibers through the outer chiasma in the medulla. $b$, Frontal section through the lamina and outer chiasma showing Glu-LI monopolar cells. The somata $(S)$ are clustered grapelike around the tracheal invaginations. All scales, $50 \mu \mathrm{m}$.

lamina and the chiasma into the medulla show Glu-LI (Fig. 5). In the medulla, Glu-LI is restricted to the layer that contains monopolar cell terminals. No other Glu-LI columnar or tangential cell type could be identified in the medulla. The third optic neuropile, the lobula, does not contain Glu-LI columnar fiber elements. However, Glu-LI wide-field fibers interconnect the lobula mainly with the posterior parts of the proto- and deutocerebrum (Fig. 6b). The optic tubercle is a glomerular structure that lies about the antennal lobe (Fig. $6 a$ ) near the anterior base of the optic lobes, and is connected to the lobula by the anterior optic tract. Glu-LI fibers were found in the anterior optic tract, the tubercle, and the intertubercle tract, which links the tubercles of both brain hemispheres. However, it was not possible to attribute the Glu-LI within the mentioned neuropiles to any of the fiber types described in the literature (DeVoe et al., 1982).

\section{Mushroom bodies}

The protocerebrum constitutes the largest part of the insect brain and incorporates several structured neuropiles. The mushroom bodies are the most prominent neuropilar masses in the dorsal protocerebrum (Fig. 4a) and contain about 170,000 parallel projecting intrinsic Kenyon cells (Kenyon, 1896; Witthöft, 1967) and the arborizations of extrinsic fibers that link the mushroom bodies to other brain areas. The calyces are predominantly described as sensory input regions, while the $\alpha$ - and $\beta$-lobes are thought to be output regions of the mushroom bodies (Mobbs, 1982, 1984; Schürmann, 1974). The calycal neuropile can be subdivided into lip, collar, and basal ring regions, which differ with respect to afferent sensory modalities. Antennal sensory input is restricted to the lip, whereas the collar receives mainly visual input (Mobbs, 1982, 1984).

The mushroom body neuropile generally shows very low levels of staining compared with the surrounding protocerebral neuropile (Figs. $6 a, 7 a$ ). The calycal lip region displays a faint granular Glu-LI that contrasts with the unstained collar and basal ring (Fig. 7a). We assume this staining to be of intrinsic origin, since a cluster of Kenyon cell bodies in the anterior medial part of the calyces is labeled (Fig. $6 a$ ). It should be stressed that the intensity of this immunoreactivity is much lower than that of the Glu-LI of motor neurons or monopolar cells. The mushroom bodies also contain a set of about 110 extrinsic GABA-LI fibers, which link the $\alpha$-lobe with the calyces via the protocerebrocalycal tract (PCT) (Bicker et al., 1985; Schäfer and Bicker, 1986a). The PCT, with its bundled neurites, as well as its varicose arborizations in the calyces, does not show Glu-LI (Fig. 6a).

\section{Ocellar interneurons}

The ocellar neuropile in the median protocerebrum integrates mainly visual information from 3 dorsal ocelli (Fig. $4 a$ ), but also receives connections from other parts of the brain-for instance, the optic lobes (Goodman, 1981). The axons of the ocellar photoreceptors project onto 30 large interneurons (Lneurons) and about 80 small interneurons (S-neurons). Five pairs of $\mathrm{L}$-neurons ( $\mathrm{L}_{\mathrm{D}}$-neurons) connect the brain with the ven-

$\overline{M B}$, mushroom body; $M C$, median calyx; $M e$, medulla; $M N$, motor neurons; $M o C$, monopolar cells; $O c$, ocelli, $O e$, esophagus; $O N$, ocellar neurons; $O T$, optic tubercle; $P B$, protocerebral bridge; $R e$, retina; $S O G$, subesophageal ganglion. Scale, $100 \mu \mathrm{m}$. $b$, Frontal section through the antennal lobe. Glu-LI axonal bundles of motor neurons $(M N)$ gather at the ventral tip of the antennal lobe and leave through the antennal and inner motor antennal nerve. No Glu-LI is shown in the lateral soma rind $(L S)$, whereas some Glu-LI containing somata $(S)$ are found in a dorsomedian position. $c$, Sagittal section through the dorsal lobe $(D L)$ and antennal lobe $(A L)$. Dendritic processes of motor neurons $(M N)$ fill the neuropile of the dorsal lobe and project ventrally through the antennal lobe to the antennal nerves. Glu-LI-positive somata $(S)$ in soma rind. $d$, Cross section of the antennal nerve showing 3 discrete Glu-LI-positive motor axons $(M N)$ and a patchy distribution of bundles of axons containing Glu-LI. $e$, Branches of the inner motor antennal nerve with Glu-LI motor axons innervating an antennal muscle. All scales, $50 \mu \mathrm{m}$. 

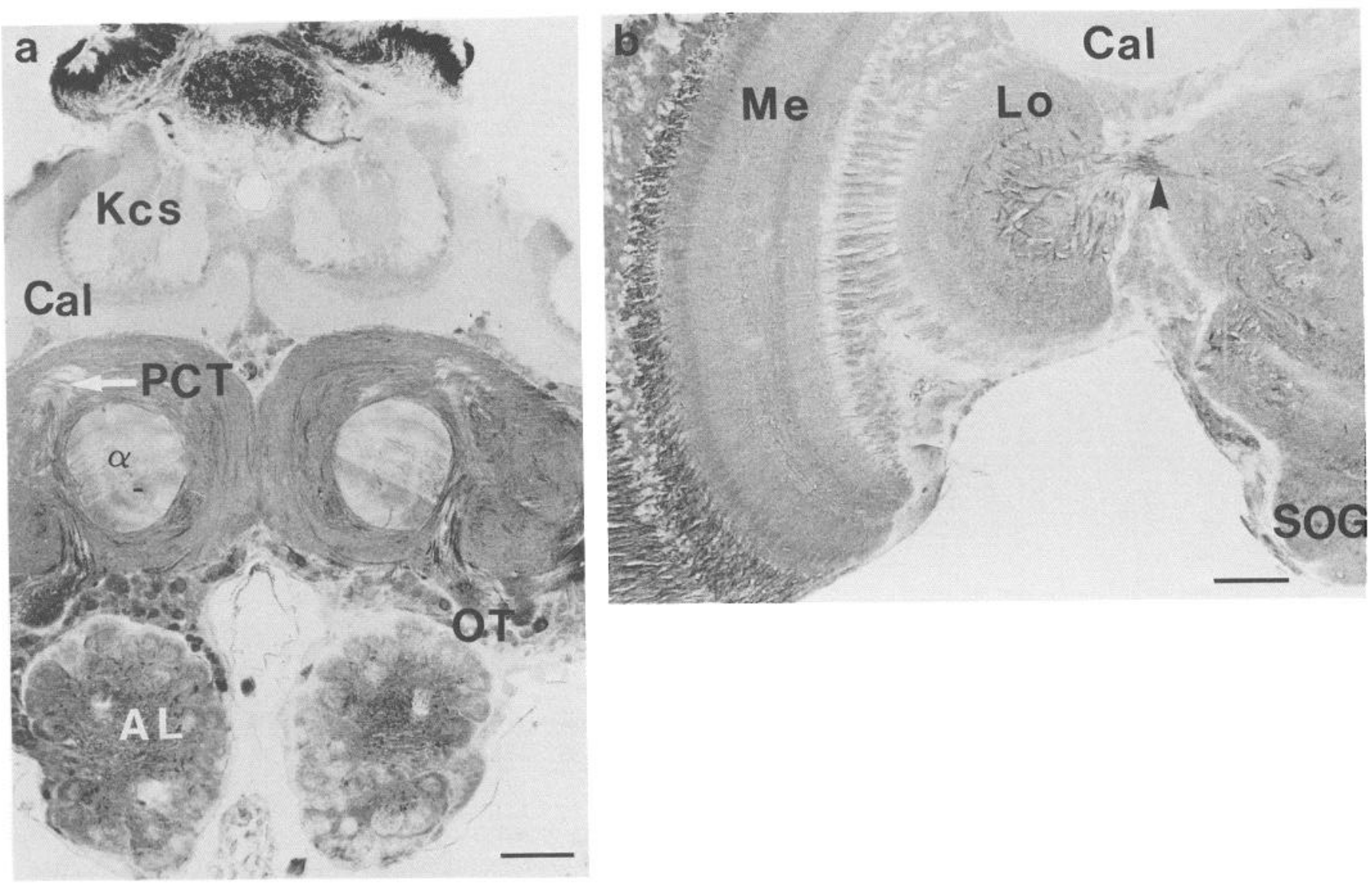

Figure 6. Survey of Glu-LI in neuropiles of the central brain and optic lobes of the honeybee. $a$, Glu-LI in central brain neuropiles. The optic tubercles $(O T)$ contain Glu-LI fibers. The $\alpha$-lobe neuropile $(\alpha)$ contains rather low levels of staining. The calycal neuropile $(\mathrm{Cal})$ shows only faint labeling except for the lip region, which is similar in staining intensity to that of the medial cluster of Kenyon cell somata (Kcs). No labeling is found in the protocerebrocalycal tract $(P C T) . b$, Glu-LI in the medulla $(M e)$, lobula $(L o)$, posterior protocerebrum, and subesophageal ganglion $(S O G)$. Glu-LI fibers (arrow) extend from the lobula into the posterior protocerebrum. No reactivity is seen in the calyx ( $\mathrm{Cal}$ ). All scales, $100 \mu \mathrm{m}$.

tral nerve cord, while the remaining 20 interneurons arborize ventrally to the protocerebral bridge in the posterior slope neuropile (Goodman, 1981). The L-neurons, which have a diameter of $12-15 \mu \mathrm{m}$, show strong Glu-LI, comparable to the intense staining of the motor axons (Fig. 7). A frontal section shows the course of the Glu-LI L-neurons within the ocellar tract and their arborizations in the posterior slope neuropile (Fig. 7a). Two of the labeled descending $L_{D}$-neurons that cross close to the esophagus to the contralateral brain hemisphere can also be discerned. Four of the five descending ocellar neurons cross to the contralateral side and project within the median dorsal tract (MDT) through the subesophageal ganglion to the thoracic ganglia, while one $L_{D}$-neuron remains in the ipsilateral side, with its axon extending in the lateral dorsal tract (LDT) (Goodman, 1981). The MDT is completely filled with Glu-LI fibers (Fig. 8c) and Glu-LI axons can also be found within the LDT. Thus, it is likely that all $\mathrm{L}_{\mathrm{D}}$-neurons show Glu-LI. The somata of the ocellar interneurons lie ventral to the calyces close to the protocerebral bridge. A section, horizontally cut through the brain at a level just above the protocerebral bridge, shows the labeled fiber profiles of the L-neurons within the ocellar tract and their Glu-LI somata (Fig. $7 \mathrm{c}$ ). The staining intensity of the protocerebral bridge is comparable to that of the remaining protocerebral neuropile.

\section{Descending neurons and the subesophageal ganglion}

The brain communicates with the motor centers in the ventral nerve chord by means of plurisegmental descending interneurons. Cobalt backfills of the connectives between the subesophageal and thoracic ganglia stain at least 100 descending neurons whose somata are clustered in groups within the brain (Schürmann, 1982). Some of these descending neurons have been identified by intracellular dye injection (Goodman et al., 1987), and were found to be motion-sensitive. Their soma position coincides with that of a number of immunoreactive cell bodies ventral to the calyces in the posterior protocerebrum (Fig. $4 a$ ). The descending movement-sensitive neurons have dendritic arborizations in the posterior slope and project in the MDT through the subesophageal ganglion into the ventral nerve chord. A horizontal section through the brain at a level where the cervical connective exits the subesophageal ganglion shows Glu-LI in the large-diameter fibers of the descending neurons (Fig. 8a). In the MDT, all of the approximately 16 fibers with a diameter greater than $10 \mu \mathrm{m}$ showed Glu-LI (Fig. $8 c$ ). The cross section through the subesophageal ganglion also revealed Glu-LI fibers in other longitudinal tracts, such as the dorsal median tract (DMT), the dorsal intermediate tracts (DIT), and the LDT. All these tracts contain descending neurons. The LDT contains the 

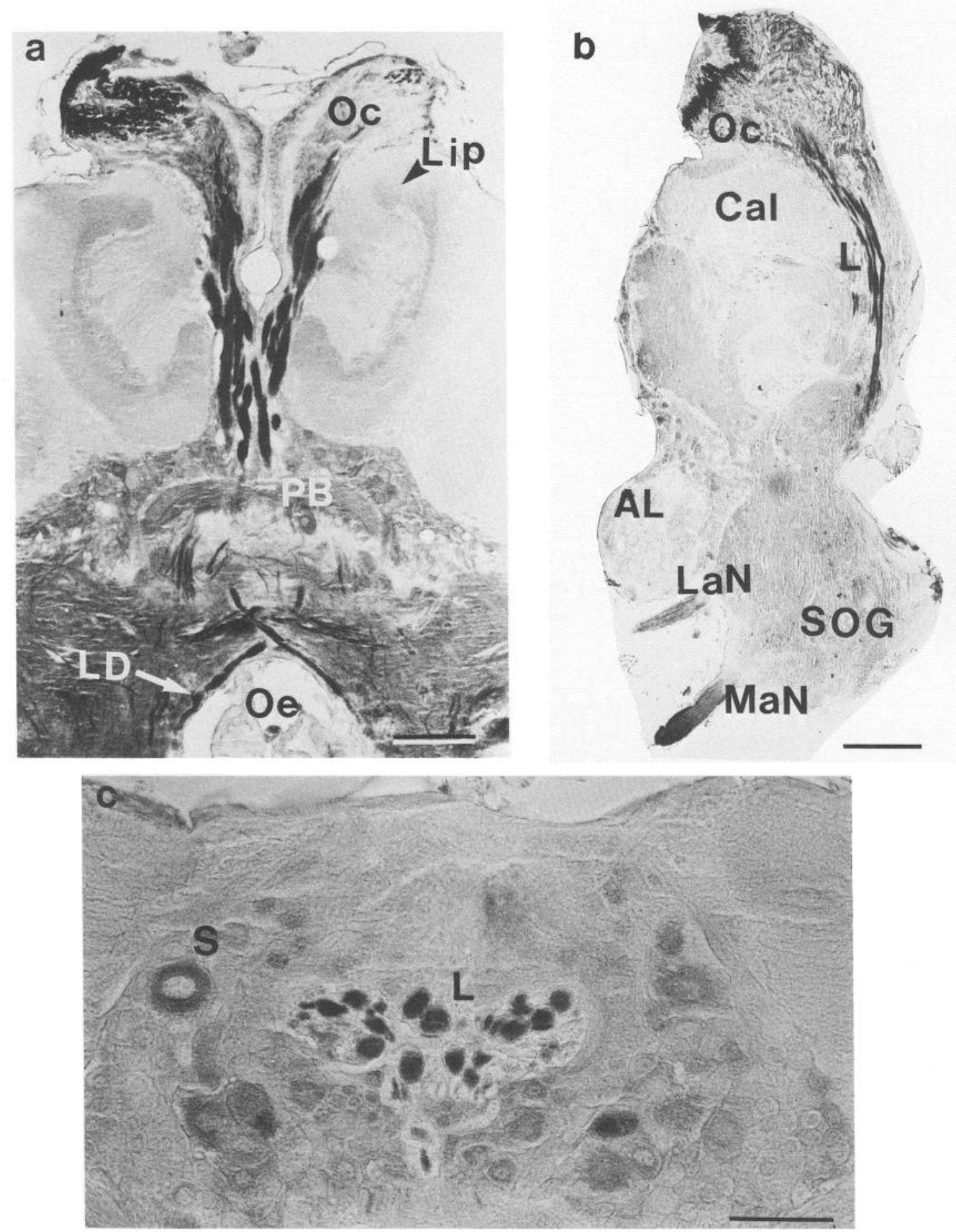

Figure 7. Glu-LI in the ocellar system of the honeybee. $a$, Frontal section through the ocellar tract. Glu-LI L-neurons project from the ocellar plexus $(O c)$ in a bundle to the posterior brain dorsal to the esophagus $(O e)$. Descending ocellar neurons $(L D)$ cross to the contralateral hemisphere. Several somata are labeled in the vicinity of the protocerebral bridge $(P B)$. The lip region $(L i p)$ of the calyces is slightly labeled. Scale, $100 \mu \mathrm{m} . b$, Sagittal section through the brain and subesophageal ganglion of the honeybee. Glu-LI in ocellar L-neurons $(L)$ can be compared to Glu-LI of motor neurons in labrofrontal nerve $(L a N)$ and mandible nerve $(M a N)$. $A L$, antennal lobe; $S O G$, subesophageal ganglion; $O c$, ocellus. Scale, 200 $\mu \mathrm{m}$. $c$, Horizontal section through the ocellar tract showing Glu-LI of large ocellar neurons $(L)$, and surrounding unlabeled, as well as labeled, somata $(S)$. Scale, $50 \mu \mathrm{m}$.

one ipsilateral projecting ocellar $\mathrm{L}_{\mathrm{D}}$ interneuron (Goodman, 1981 ), and the DIT contains descending neurons that arborize in the dorsal lobe and posterior slope, with their somata located in the dorsal soma rind of the antennal lobes (Fig. 4a). Intra- cellular recordings and staining show that these neurons respond to visual stimulation of the compound eyes and to directionally dependent mechanical stimulation of the antennae (G. Bicker, unpublished observations). Correspondingly, Glu-LI somata 

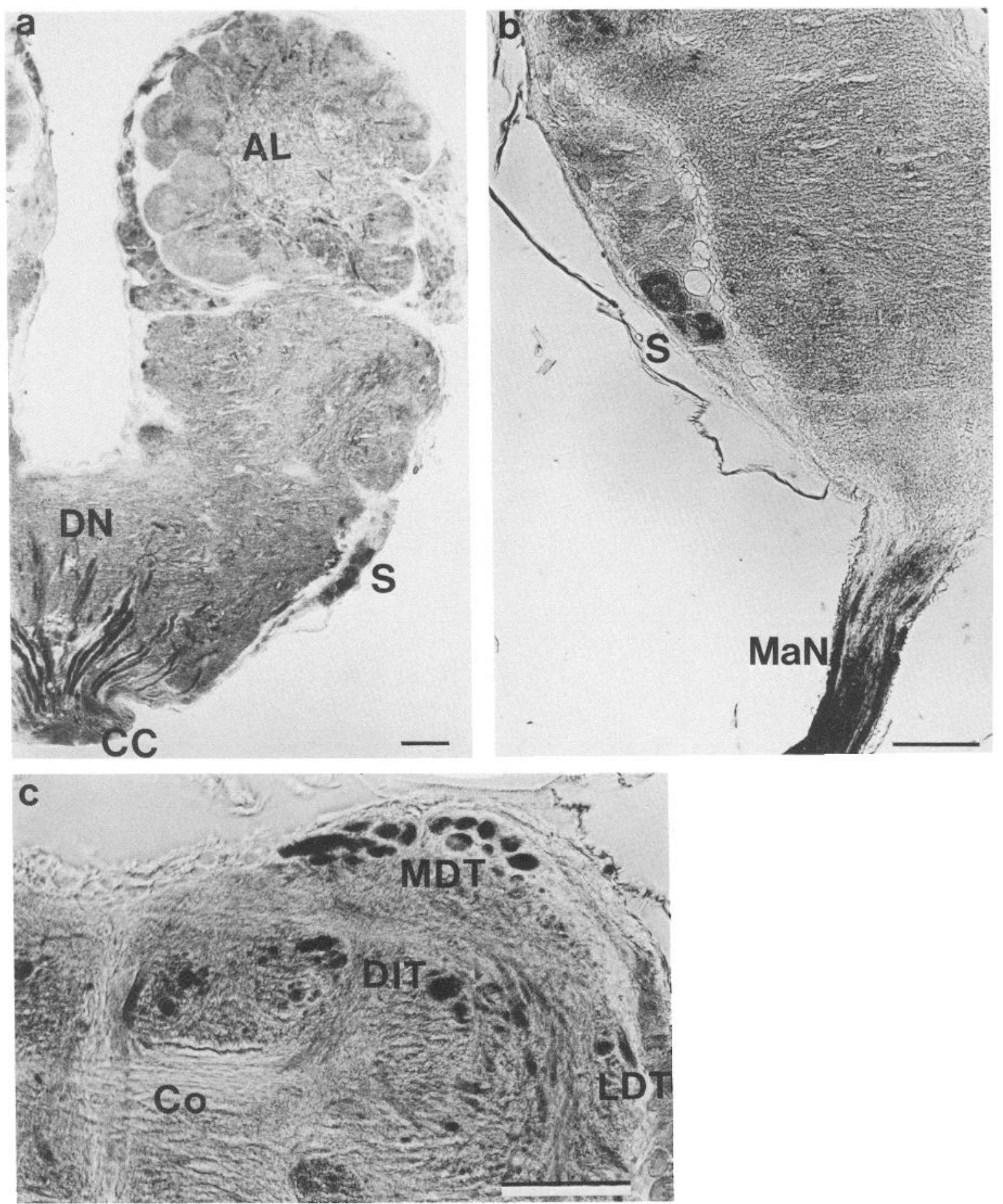

Figure 8. a, Horizontal section through the brain of the honeybee at the level of the antennal lobe $(A L)$. Glu-LI descending neurons $(D N)$ gather in the dorsal subesophageal ganglion and project through the cervical connective $(C C)$ to the ventral nerve chord. Glu-LI somata $(S)$ are found in the lateral soma rind. $b$. Frontal section through the mandibular neuromere, showing Glu-LI motor neurons in the mandible nerve (MaN) and their corresponding somata $(S)$ in the lateral soma layer. $c$, Frontal section through the dorsal labial neuromere of the subesophageal ganglion. GluLI large-diameter axons are found in the median dorsal tract $(M D T)$, the dorsal intermediate tract $(D I T)$, and the lateral dorsal tract $(L D T)$. No staining was found in the commissure $(\mathrm{Co})$. All scales, $50 \mu \mathrm{m}$.

were found in the dorsal soma rind of the antennal lobe (Fig. $4 a$ ). This area also contains somata of a second group of descending neurons with characteristic morphology. We found Glu-LI somata that send primary neurites dorsally in the loop around the $\alpha$-lobe (Fig. $4 a$ ). Even though we could not trace these neurons continuously to the ventral chord, it remains a distinct possibility that the Glu-LI somata of the dorsal antennal soma rind belong to 2 groups of descending neurons, one with a posterior-directed primary neurite that projects below the $\alpha$-lobe, while the second has a primary neurite looping around the $\alpha$-lobe before it dives between the central body and $\beta$-lobe to the posterior brain parts (Fig. $4 a$ ). 
The subesophageal ganglion is contiguous with the deuto- and tritocerebral parts of the brain (Fig. 4a) and arises from the embryonic fusion of 3 neuromeres: mandibular, maxillary, and labial. It innervates various mouth parts through the corresponding mandibular, maxillary, and labial nerves. These nerves contain Glu-LI in the axons of the motor neurons that comprise the large-diameter fibers within the nerves. A cross section of the mandibular nerve shows the Glu-LI in the motor axons. The somata of the mandibular motor neurons are located in the lateral soma layer of the mandibular neuromere (Fig. 8b) (Rehder, 1987). A frontal section of the mandibular neuromere shows 3 distinctly labeled somata in a site where the mandibular motor neurons can be found by cobalt backfilling of the nerve (Rehder, 1987).

\section{Cell-specific metabolic pathways}

Similar to the vertebrate nervous system, GABA is formed in locust and honeybee neurons from glutamate by its biosynthetic enzyme glutamate decarboxylase (Fox and Larsen, 1972; Emson et al., 1974; Breer and Heilgenberg, 1985). During recent investigations of GABA-LI in the visual system of the bee (Schäfer and Bicker, 1986a, b) we encountered several cases of monopolar cells displaying GABA-LI. It is difficult to estimate the frequency of GABA-LI-positive monopolar cells since we did not particularly search for them. An example of a GABA-LI monopolar cell is shown in Figure 9. According to our present investigations, monopolar cells are Glu-LI (Fig. 5, $a, b$ ) and this implies a rather high level of glutamate within these cells. An accidental expression of the GAD enzyme could lead to the conversion of glutamate into GABA, causing the switch into the GABA-LI phenotype. For obvious reasons, it is impossible to determine whether this unusual expression of GABA-LI corresponds to a real switching between 2 transmitter phenotypes. Nevertheless, the occasional expression of GABA-LI by some monopolar cells provided the first clue that glutamate, a metabolic precursor of GABA, is concentrated in normal monopolar cells.

\section{Discussion}

\section{Locust metathoracic ganglion}

A rather straightforward approach toward visualizing neurotransmitters in tissue is the use of transmitter-specific antisera. However, the localization of "transmitter-like" immunoreactivity in certain cell populations does not necessarily imply a function as transmitter for the immunoreactive substance. Especially amino acids such as glutamate serve multiple functions in general metabolism apart from their roles as a transmitter. Nevertheless, Glu-LI may be a useful marker for glutamatergic neurons, because, under certain conditions, Glu-LI is concentrated in several vertebrate neurons assumed to use glutamate as a transmitter (Storm-Mathisen et al., 1983; Ottersen and Storm-Mathisen, 1985; Somogyi et al., 1986). We tested whether this antiserum stains identifiable neurons in an invertebrate nervous system that have already been classified as glutamatergic, GABAergic, or octopaminergic by independent pharmacological evidence.

Most of the motor neurons in crustaceans and insects are considered to be glutamatergic. We studied Glu-LI in neurons that innervate the fast extensor tibiae muscle of the locust. This muscle constitutes a convenient system for the study of neuromuscular transmission of identifiable excitatory glutamatergic, inhibitory GABAergic, and modulatory octopaminergic

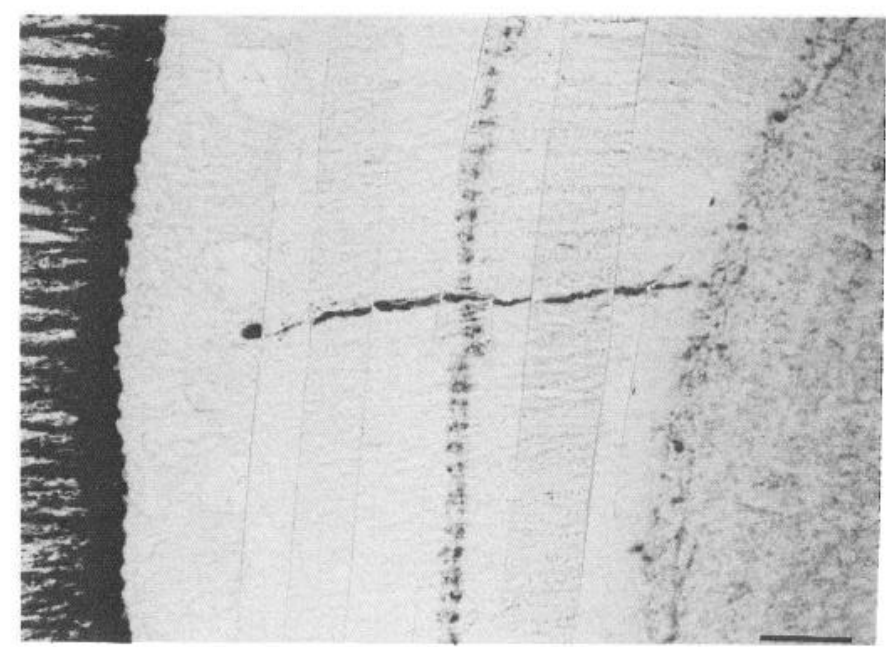

Figure 9. GABA-LI in optic ganglia. Composite micrograph from adjacent frontal section through the optic ganglia of the honeybee. A single GABA-LI monopolar cell extends from the fenestrated layer across the GABA-LI external plexiform layer C to the medulla. Scale, $25 \mu \mathrm{m}$.

motor neurons (Usherwood and Grundfest, 1965; Evans and O'Shea, 1977; Usherwood, 1978; Goodman and Spitzer, 1979; Hoyle, 1983; Piek, 1985). The glutamate antiserum stains the identified excitatory motor neuron FETi, which displays a higher level of immunoreactivity than that of the common inhibitory neuron (CI) and the dorsal unpaired median cells (Fig. 1). Since glutamate is the metabolic precursor of GABA, it is interesting to compare glutamatergic and GABAergic cells with respect to their contents of Glu-LI. Besides the inhibitory motor neurons, the thoracic ganglia contain numerous GABA-LI interneurons (Watson, 1986). We investigated Glu-LI in a large sample of GABA-LI neurons by means of double-labeling experiments (Fig. 3). These experiments address the question of to what extent GABA-LI cells show Glu-LI, and how well the 2 antisera discriminate between glutamatergic and GABAergic neurons. In a first step, Glu-LI was detected in neurons by a brown reaction product, and then GABA-LI by a blue reaction product. This method confirmed earlier findings by Watson (1986) that the inhibitory motor neurons show GABA-LI. The sequential comparison of Glu-LI and GABA-LI on the same section demonstrated a very low level of Glu-LI in the common inhibitor but also in many other GABA-LI neurons. Storm-Mathisen and Ottersen (1986) reported similar findings for the vertebrate brain, where tissue elements high in GABA-LI are generally low in Glu-LI. Conceivably, the free glutamate in these cells is kept low by the action of GAD, the enzyme that converts glutamate to GABA. According to the estimates of Breer and Heilgenberg (1985), the concentration of GAD is 5-10 times higher in the locust nervous system than in the mouse cortex and cerebellum, with a specific activity 16 times higher in the locust nervous system than in the mouse brain. The finding of a low Glu-LI in presumed octopaminergic neurons shows that this property is not restricted to the nonglutamatergic cells that use GABA as transmitter. However, we cannot generalize from these data to conclude that Glu-LI is low in all nonglutamatergic insect neurons, since the possibility remains that some neurons may be enriched in nonreleasable glutamate because of special metabolic demands. This may, for example, explain the relatively high Glu-LI in certain cholinergic cell groups in perfusion-fixed mammalian brains (Ottersen and Storm-Mathisen, 1984). 
No attempts were made to distinguish between glutamate serving in the intermediary metabolism and glutamate in the transmitter pool. Ottersen and Storm-Mathisen (1985) suggested that the transmitter pool may be preferentially visualized in immersion-fixed brain slices, while in perfusion-fixed material the staining reflects the total concentration of the amino acids. Since we did not systematically alter the fixation conditions, no comparison can be drawn to the situation in vertebrate brain.

\section{Honeybee brain}

Deutocerebrum and subesophageal ganglion. Glutamate is the most abundant free amino acid in the brain of the honeybee (Frontali, 1964). Thus its immunocytochemical localization is desirable in order to compare it to that of other free amino acids like GABA (Schäfer and Bicker, 1986a). GABAergic neurons can be visualized by antisera against the GABA-forming enzyme $\mathrm{G} \Lambda \mathrm{D}$. This approach has becn successfully applicd to the brain of the bee (Bicker et al., 1987) with an antiserum raised against GAD from rat brain (Oertel et al., 1981). The GAD antiserum gave a distribution of immunoreactivity similar to that produced by the GABA antiserum. Unfortunately, glutamate-forming enzymes are not specific for glutamatergic neurons (Wenthold and Altschuler, 1983) and thus we used an antiserum that was directly raised against glutamate-protein conjugate (StormMathisen et al., 1983).

Some populations of neurons, like the motor neurons of the subesophageal ganglion and the brain, display a high level of Glu-LI (Figs. 4, 7b, 8b). The nerves of the sub- and supraesophageal ganglia are composed of both sensory and motor axons. Glu-LI was found mainly in the motor fibers, these being of larger diameter than the sensory fibers. We suggest that, in accordance with the results obtained in the locust, the majority of motor neurons use glutamate as a transmitter. Biochemical and pharmacological investigations in several insect species (Callec, 1974; Sanes and Hildebrand, 1976; Buchner and Rodrigues, 1983) have led to the hypothesis that ACh may be the major transmitter of antennal and cercal sensory afferents. Indeed, Glu-LI was very low in the small-diameter fibers of the antennal nerve that presumably are the axons of the chemoreceptors. Some staining of intermediate intensity was found in fibers of medium diameter. The Glu-LI of the dorsal lobe can be largely attributed to motor neurons, but some of the descending interneurons that ramify in this neuropile may also contribute to the dense reactivity. In contrast to the many GABALI local interneurons that arborize within the glomeruli of the antennal lobe (Schäfer and Bicker, 1986a), very few Glu-LI fibers could be detected in the neuropile of the antennal lobe.

Visual and ocellar system. Glutamate has been implicated as a neurotransmitter of vertebrate photoreceptors (Miller and Slaughter, 1986). We could not detect significant levels of GluLI in the photoreceptor cells of the bee's compound eye and ocelli. It remains to be determined how widely this observation can be generalized across the various insect orders. In contrast to the abundance of GABA-LI in higher-order visual interneurons, only the monopolar cells in the lamina and wide-field fibers of the lobula show clear Glu-LI. The intensity of the staining in these neurons is comparable to that of the motor neurons. In Drosophila, high-affinity ${ }^{3} \mathrm{H}$-glutamate binding sites have been demonstrated by autoradiography for the neuropile, but not the retina. The histochemical analysis of several enzymes thought to be involved in glutamate metabolism, however, revealed rather high levels of enzyme activity in the retina and the lamina (Chase and Kankel, 1987). Monopolar cells are first-order interneurons of the visual system, and, apart from the long visual fibers, they constitute the main centripetal input channel into the second optic ganglion, the medulla. We could not discern other GluLI cell types within the medulla. Glu-LI was also found in widefield fibers of the lobula. However, the anatomical relations between the Glu-LI and the GABA-LI wide-field fibers (Schäfer and Bicker, 1986a) could not be determined. In contrast to the many GABA-LI strata found in all 3 optic ganglia, the Glu-LI fibers are less abundant. A certain similarity between the visual system of the compound eyes and the ocellar system with respect to the distribution of GABA-LI has already been noted (Schäfer and Bicker, 1986a,b): neither the photoreceptors nor the firstorder interneurons were labeled, but GABA-LI fibers of presumably efferent nature approached the first-order interneurons in both neuropiles. The present investigation shows that the first-order interneurons in the visual and the ocellar system contain Glu-LI. This similarity in the distribution of amino acid-I I extends even further. The various photoreceptor types in the visual and ocellar systems of the bee all display taurineLI (Schäfer et al., 1988). Thus, the morphological distinctions between cell types such as photoreceptors, first-order interneurons, and efferent interneurons are paralleled by the results of the immunocytochemical dissection of the visual system with respect to neuroactive substances. The developmental origin and functional implication of the similarity of the chemical neuroanatomy of the visual and ocellar systems remain unknown, but deserve further investigation.

\section{Mushroom bodies}

This work provides the first evidence that the chemical composition of the intrinsic Kenyon cells of the mushroom body ncuropile may be heterogeneous. This assumption is derived from a differential staining of the calycal neuropile in the lip region (Figs. 6a, 7a) and the corresponding cluster of Kenyon cell somata in the anterior median parts of calyces. The staining is, however, rather faint and not comparable to the intensity of staining found in motor neurons. According to Mobbs (1982), the parallel projecting Kenyon cells of the lip region map to the more ventral layer of the $\alpha$-lobes. The layered staining that was found in the ventral and dorsal layers is difficult to interpret, however, since both intrinsic and extrinsic fibers contribute to the laminar appearance of the transected lobe. The interpretation that the faint staining of the lip region is of intrinsic origin is supported by the fact that the main sensory input projections into the calyces, the anterior superior optic tract from the visual system and the median and lateral antennoglomerular tract from the antennal lobe do not show Glu-LI. This is also true for the rather prominent group of about 110 GABA-LI-positive PCT interneurons.

\section{Descending pathways}

Schäfer and Bicker (1986a) reported GABA-LI fibers in the cervical connective that link the subesophageal ganglion to the thoracic ganglia, and suggested that some of them were likely to be descending. Meanwhile, a combination of Lucifer yellow backfilling of the connective and immunocytochemical staining to GABA-LI revealed that the GABA-I I descending neurons originate only from the subesophageal ganglion (Bicker et al., 1987). We could not find GABA-LI in the large-diameter descending neurons of the brain, but our present study revealed Glu-LI descending neurons originating in the brain. The Glu- 
LI descending cells of the MDT have the largest axonal diameter found within the cervical connective, and intracellular recordings combined with dye injection have been performed (Goodman et al., 1987). Thus, immunocytochemical demonstration of some major Glu-LI pathways that connect the brain to the thoracic ganglia raises the question as to whether these pathways are glutamatergic. Descending neurons in the locust are known to make excitatory short-latency connections to thoracic neurons that can now be analyzed by a combined immunocytochemical and pharmacological approach.

\section{Conclusion}

Polyclonal antibodies specific for glutaraldehyde-fixed glutamate have been shown to label selected neuronal types in the locust metathoracic ganglion and honeybee brain, including cells previously classified as glutamatergic according to physiological criteria. Glu-LI was low in neurons displaying GABA-LI and considered to be GABAergic, as well as in an identified cluster of neurons thought to use a transmitter different from glutamate and GABA. Compared to perfusion-fixed mammalian brain, which shows considerable Glu-LI in most neuronal populations (Ottersen and Storm-Mathisen, 1984), insect nerve tissue exhibits a more differentiated pattern of Glu-LI distribution. These results would suggest that in insect neural tissue the transmitter pool of glutamate is less confounded by "metabolic" glutamate than is the case in mammalian brain, due either to real concentration differences or, possibly, to the unavoidable differences in conditions for fixation. Whatever the reason, the present data indicate that Glu-LI is more useful as a marker for glutamatergic neurons in insects than in vertebrates, at least when standard light-microscopic preparations are used. However, recent technical advances (Somogyi et al., 1986; Storm-Mathisen and Ottersen, 1987) offer hope for the use of Glu-LI as a glutamatergic marker in mammals as well.

\section{References}

Ammermüller, J., and R. Weiler (1985) S-neurons and not L-neurons are the source of GABAergic action of the ocellar retina. J. Comp. Physiol. A 157: 779-788.

Bicker, G., S. Schäfer, and T. G. Kingan (1985) Mushroom body feedback interneurons in the honeybee show GABA-like immunoreactivity. Brain Res. 360: 394-397.

Bicker, G., S. Schäfer, and V. Rehder (1987) Chemical neuroanatomy of the honeybee brain. In Neurobiology and Behavior in Honeybees, R. Menzel and A. R. Mercer, eds., pp. 202-224, Springer-Verlag, Berlin, Heidelberg, New York, Tokyo.

Breer, H., and H. Heilgenberg (1985) Neurochemistry of GABAergic activities in the central nervous system of Locusta migratoria. J. Comp. Physiol. A 157: 343-354.

Buchner, E., and V. Rodrigues (1983) Autoradiographic localization of ${ }^{3} \mathrm{H}$-choline uptake in the brain of Drosophila melanogaster. Neurosci. Lett. 42: 25-31.

Burrows, M., and G. Hoyle (1973) Neural mechanisms underlying behavior in the locust Schistocerca gregaria. III. Topography of limb motorneurons in the metathoracic ganglion. J. Neurobiol. 4: 167186.

Callec, J. J. (1974) Synaptic transmission in the central nervous system of insects. In Insect Neurobiology, J. E. Treherne, ed., pp. 119-185, Elsevier, Amsterdam.

Chase, B. A., and D. R. Kankel (1987) A genetic analysis of glutamatergic function in Drosophila. J. Neurobiol. 18: 15-41.

Cull-Candy, S. G. (1976) Two types of extrajunctional L-glutamate receptors in the locust muscle fibres. J. Physiol. (Lond.) 255: 449464.

DeVoe, R. D., W. Kaiser, J. Ohm, and L. S. Stone (1982) Horizontal movement detcctors of honeybees: Directionally selective visual neurons in the lobula and brain. J. Comp. Physiol. A 147: 155-170.
Emson, P. C., M. Burrows, and F. Fonnum (1974) Levels of glutamatc decarboxylase, acetyltransferase, and acetylcholine esterase in identified motor neurons in the locust. J. Neurobiol. 5: 33-42.

Evans, P. D., and M. O'Shea (1977) An octopaminergic neurone modulates neuromuscular transmission in the locust. Nature 270: 257259.

Fonnum, F. (1984) Glutamate: A neurotransmitter in mammalian brain. J. Neurochem. 42: 1-11.

Fox, P. M., and J. R. Larsen (1972) Glutamic acid decarboxylase and the GABA shunt in the supraoesophageal ganglion of the honeybee, Apis mellifera. J. Insect Physiol. 18: 439-457.

Frontali, N. (1964) Brain glutamic acid decarboxylase and synthesis of GABA in vertebrate and invertebrate species. In Comparative Neurochemistry, D. Richter, ed., pp. 185-192, Pergamon, Oxford, UK.

Goodman, C. S., and N. C. Spitzer (1979) Embryonic development of identified neurons: Differentiation from neuroblast to neuron. Nature 280: 208-214.

Goodman, L. J. (1981) Organization and physiology of the insect dorsal ocellar system. In Handbook of Sensory Physiology, vol. 7, 6C, H. Autrum, ed., pp. 201-286, Springer-Verlag, Berlin, Heidelberg.

Goodman, L. J., W. A. Fletcher, R. G. Guy, P. G. Mobbs, and C. D. J. Pomfrett (1987) Motion sensitive descending interneurons, ocel$\operatorname{lar} \mathrm{L}_{\mathrm{D}}$ neurons, and neck motorneurons in the bee: A neural substrate for visual course control in Apis mellifera. In Neurobiology and Behavior in Honeybees, R. Menzel and A. R. Mercer, eds., pp. 158-171, Springer-Verlag, Berlin, Heidelberg, New York, Tokyo.

Hale, J. P., and M. Burrows (1985) Innervation patterns of inhibitory motorneurones in the locust. J. Exp. Biol. 117: 401-413.

Hertz, L., E. Kvamme, E. G. McGeer, and A. Schousboe (1983) Glutamine, Glutamate, and GABA in the Central Nervous System, Liss, New York.

Hodgson, A. J., B. Penke, A. Erdei, I. W. Chubb, and P. Somogyi (1985) Antisera to $\gamma$-aminobutyric acid. J. Histochem. Cytochem. 33: 229239.

Homberg, U., T. G. Kingan, and J. G. Hildebrand (1987) Immunocytochemistry of GABA in the brain and subesophageal ganglion of Manduca sexta. Cell Tissue Res. 248: 1-24.

Hoskins, S. G., U. Homberg, T. G. Kingan, T. A. Christensen, and J. G. Hildebrand (1986) Immunocytochemistry of GABA in the antennal lobes of the sphinx moth Manduca sexta. Cell Tissue Res. 244: 243-252.

Hoyle, G. (1955a) The anatomy and innervation of locust skeletal muscle. Proc. R. Soc. [Biol.] 143: 281-292.

Hoyle, G. (1955b) Neuromuscular mechanism of a locust skeletal muscle. Proc. R. Soc. [Biol.] 143: 343-367.

IIoyle, G. (1975) Evidence that insect dorsal unpaired median (DUM) neurons are octopaminergic. J. Exp. Zool. 193: 425-431.

Hoyle, G. (1978) Distributions of nerve and muscle fibre types in locust jumping muscle. J. Exp. Biol. 73: 205-233.

Hoyle, G. (1983) Muscles and their Neural Control, Wiley, New York.

Hoyle, G., and M. Burrows (1973) Neural mechanisms underlying behavior in the locust Schistocerca gregaria. I. Physiology of identified motorneurons in the metathoracic ganglion. J. Neurobiol. 4: 3-41.

Kenyon, F. G. (1896) The brain of the bee. A preliminary contribution to the nervous system of the Arthropoda. J. Comp. Neurol. 6: 133210.

Meyer, E. P., C. Matute, P. Streit, and D. R. Nässel (1986) Insect optic lobe neurons identifiable with monoclonal antibodies to GABA. Histochemistry 84 : 207-216.

Miller, R. F., and M. M. Slaughter (1986) Excitatory amino acid receptors of the retina: Diversity of subtypes and conductance mechanisms. Trends Neurosci. 9: 211-218.

Mobbs, P. G. (1982) The brain of the honeybee Apis mellifera. I. The connections and spatial organization of the mushroom bodies. Philos. Trans. R. Soc. Lond. (Biol.) 298: 309-354.

Mobbs, P. G. (1984) Neural networks in the mushroom bodies of the honeybee. J. Insect Physiol. 30 (No. 1): 43-58.

Oertel, W. H., D. E. Schmechel, E. Mugnaini, M. L. Tappaz, and I. J. Kopin (1981) Immunocytochemical localization of glutamate decarboxylase in rat cerebellum with a new antiserum. Neuroscience 6 : $2715-2735$.

O'Shea, M. (1985) Are skeletal motorneurons in arthropods peptidergic? In Model Neural Networks and Behavior, A. I. Selverston, ed., pp. 401-413, Plenum, New York.

Otsuka, M., E. A. Kravitz, and D. D. Potter (1967) Physiological and 
chemical architccture of a lobster ganglion with particular reference to gamma-aminobutyrate and glutamate. J. Neurophysiol. 30:725752 .

Ottersen, O. P., and J. Storm-Mathisen (1984) Glutamate- and GABAcontaining neurons in the mouse and rat brain, as demonstrated with a new immunocytochemical technique. J. Comp. Neurol. 229: 374392.

Ottersen, O. P., and J. Storm-Mathisen (1985) Different neuronal localization of aspartate-like and glutamate-like immunoreactivities in the hippocampus of rat, guinea-pig and senegalese baboon (Papio papio), with a note on the distribution of $\gamma$-aminobutyrate. Neuroscience 16: 589-606.

Ottersen, O. P., and J. Storm-Mathisen (1987) Localization of amino acid neurotransmitters by immunocytochemistry. Trends Neurosci. 10: $250-254$

Ottersen, O. P., J. Storm-Mathisen, S. Madsen, S. Skumlien, and J. Strømhaug (1986) Evaluation of the immunocytochemical method for amino acids. Med. Biol. 64: 147-158.

Pareto, A. (1972) Die zentrale Verteilung der Fühlerafferenzen bei Arbeiterinnen der Honigbiene, Apis mellifera L. Z. Zellforsch. 131: 109-140.

Pearson, K. G., and S. J. Bergman (1969) Common inhibitory motorneurons in insects. J. Exp. Biol. 50: 445-471.

Piek, T. (1985) Neurotransmission and neuromodulation of skeletal muscles. In Comprehensive Insect Physiology, Biochemistry and Pharmacology, vol. 11, G. A. Kerkut and L. I. Gilbert, eds., pp. 55-118, Pergamon, New York.

Pitman, R. M. (1985) Nervous system. In Comprehensive Insect Physiology, Biochemistry and Pharmacology, vol. 11, G. A. Kerkut and L. I. Gilbert, eds., pp. 5-54, Pergamon, New York.

Rehder, V. (1987) Zur Struktur und Funktion des Unterschlundganglions der Honigbiene. Thesis, Freie Universität, Berlin.

Ribi, W. A. (1975) The neurons of the first optic ganglion of the bee (Apis mellifera). Adv. Anat. Embryol. Cell. Biol. 50: 1-43.

Sanes, J. R., and J. G. Hildebrand (1976) Acetylcholine and its metabolic enzymes in the developing antennae of the moth, Manduca sexta. Dev. Biol. 52: 105-120.

Schäfer, S., and G. Bicker (1986a) Distribution of GABA-like immunoreactivity in the brain of the honeybee. J. Comp. Neurol. 246 . $287-300$

Schäfer, S., and G. Bicker (1986b) Common projection areas of 5-HTand $\mathrm{GABA}$-like immunoreactive fibers in the visual system of the honeybee. Brain. Res. 380: 368-370.

Schäfer, S., G. Bicker, O. P. Ottersen, and J. Storm-Mathisen (1988) Taurine-like immunoreactivity in the brain of the honeybee. J. Comp. Neurol. 268: 60-70.

Schürmann, F. W. (1974) Bemerkungen zur Funktion der Corpora Pedunculata im Gehirn der Insekten aus morphologischer Sicht. Exp. Brain Res. 19: 400-432.

Schürmann, F. W. (1982) On synaptic connexions, tracts, and compartments in the brain of the honeybee. In The Biology of Social Insects, M. D. Breed, C. D. Michener, and H. E. Evans, eds., pp. 390394, Westview Press, Boulder, CO.

Seguela, P., M. Geffard, R. M.-Buigs, and M. LeMoal (1984) Anti- bodies against $\gamma$-aminobulyric acid: Specificity studies and immunocytochemical results. Proc. Natl. Acad. Sci. USA 81: 3888-3892.

Somogyi, P., K. Halasy, J. Somogyi, J. Storm-Mathisen, and O. P. Ottersen (1986) Quantification immunogold labelling reveals enrichment of glutamate in mossy and parallel fibre terminals in cat cerebellum. Neuroscience 19: 1045-1050.

Sternberger, L. A. (1979) Immunocytochemistry, Wiley, New York.

Storm-Mathisen, J., and O. P. Ottersen (1986) Antibodies against amino acid transmitters. In Neurohistochemistry: Modern Methods and Applications, P. Panula, H. Päivärinta, and S. Soinila, eds., pp. 107-136, Liss, New York.

Storm-Mathisen, J., and O. P. Ottersen (1988) Anatomy of putative glutamatergic neurons. In Neurotransmitters and Brain Function, $\mathrm{M}$. Avoli, T. A. Reader, R. W. Dykes, and P. Gloor, eds., Plenum, New York (in press).

Storm-Mathisen, J., A. K. Leknes, A. T. Bore, J. L. Vaaland, P. Edminson, F. M. S. Haug, and O. P. Ottersen (1983) First visualization of glutamate and $\mathrm{GABA}$ in neurons by immunocytochemistry. Nature 301: $517-520$.

Suzuki, H. (1975) Antennal movements induced by odor and central projections of the antennal neurons in the honey bee. J. Insect Physiol. 6: $168-179$

Usherwood, P. N. R. (1974) Nerve-muscle transmission. In Insect Neurobiology, J. E. Treherne, ed., pp. 245-305, North Holland/Elsevier, New York.

Usherwood, P. N. R. (1978) Amino acids and synaptic transmission. Adv. Comp. Physiol. Biochem. 7: 227-309.

Usherwood, P. N. R. (1981) Glutamate synapses and receptors on insect muscle. In Glutamate as a Neurotransmitter, G. DiChiara, and D. L. Gessa, eds., pp. 183-193, Raven, New York.

Usherwood, P. N. R., and S. G. Cull-Candy (1975) Pharmacology of somatic nerve-muscle synapses. In Insect Muscle, P. N. R. Usherwood, ed., pp. 207-280, Academic, London.

Usherwood, P. N. R., and H. J. Grundfest (1965) Peripheral inhibition in skeletal muscle of insects. J. Neurophysiol. 28: 497-518.

Usherwood, P. N. R., P. Machili, and G. Leaf (1968) L-Glutamate at insect excitatory nerve-muscle synapses. Nature 219: 1169-1172.

Vandesande, F. (1983) Immunohistochemical double staining techniques. In Immunohistochemistry, A. C. Cuello, ed., pp. 257-272, Wiley, New York.

Watson, A. H. D. (1986) The distribution of GABA-like immunoreactivity in the thoracic nervous system of the locust Schistocerca gregaria. Cell Tissue Res. 246: 331-341.

Watson, A. H. D., M. Burrows, and J. P. Hale (1985) The morphology and ultrastructure of common inhibitory motor neurones in the thorax of the locust. J. Comp. Neurol. 239: 341-359.

Wenthold, R. J., and R. A. Altschuler (1983) Immunocytochemistry of aspartate aminotransferase and glutaminase. In Glutamine, Glutamate and GABA in the Central Nervous System, L. Hertz, E. Kvamme, E. G. McGeer, A. Schousboe, eds., pp. 33-50, Liss, New York.

Werman, R. (1966) Criteria for identification of a central nervous system transmitter. Comp. Biochem. Physiol. 18: 745-766.

Witthöft, W. (1967) Absolute Anzahl und Verteilung der Zellen im Hirn der Honigbiene. Z. Morphol. Tiere 61: 160-184. 